\title{
THE EFFECTS OF 1-HYDRAZINOPHTHALAZINE ON THE PULMONARY CIRCULATION IN MITRAL DISEASE
}

\author{
BY \\ J. D. AITCHISON, W. I. CRANSTON, AND ELIZABETH A. PRIEST \\ From the Royal Infirmary, Aberdeen \\ Received November 9, 1954
}

During the investigation of the effects of hypotensive agents on the pulmonary circulation in mitral stenosis, an unexpected result was observed following the administration of 1-hydrazinophthalazine (apresoline). It was found that in patients with mitral stenosis, this drug caused elevation of the pulmonary arterial pressure, while reducing the systemic arterial pressure. This effect of 1-hydrazinophthalazine may be of considerable importance in the treatment of hypertension associated with mitral disease.

\section{MATERIAL}

Twelve patients, aged 26 to 68, were investigated. Ten were suffering from rheumatic heart disease affecting the mitral valve, without other valvular involvement, and were in process of assessment for valvotomy. The predominance of stenosis or incompetence was assessed clinically and has been confirmed at operation in several cases. None was in heart failure at the time of observation. Two subjects were suffering from essential hypertension, and showed some elevation of pulmonary arterial pressure at rest; neither of these showed any evidence of rheumatic heart disease.

\section{METHODS}

Two hours before the investigation began, each patient received $500 \mathrm{mg}$. of procaine amide by mouth. One hour later, this dose was repeated and $0.2 \mathrm{~g}$. of quinalbarbitone was given. Under local anæsthesia with the patient supine, a cardiac catheter was introduced into the pulmonary artery, and 20-30 minutes were allowed for stabilization. Basal readings of mean pulmonary arterial pressure were obtained, using a saline manometer. The zero level was taken as a plane $5 \mathrm{~cm}$. below the manubriosternal junction.

An initial determination of cardiac output was carried out at this time using the Fick principle. An arterial blood sample was withdrawn from the brachial or femoral artery, and a mixed venous sample from the pulmonary artery. Blood oxygen content was measured in duplicate on each sample by the method of Roughton and Scholander (1943). Oxygen uptake was measured over a period of 3-5 min., using a Benedict-Roth spirometer.

An injection of 10-20 mg. of 1-hydrazinophthalazine was then made slowly through the catheter. Mean pulmonary arterial pressure, systemic arterial pressure (by sphygmomanometer) and pulse or ventricular rate were measured frequently. The intervals between successive observations varied from 30 seconds, when values were changing rapidly, to several minutes. Further determinations of cardiac output were made, one about the time of maximal effect of the drug. Repeated determinations of pulmonary " capillary" pressure were not made because of the difficulty of ensuring that the catheter tip was wedged in the same site on each occasion. In one subject (E.T.) cardiac output was not measured, for technical reasons. 
Total pulmonary resistance was calculated from the formula:

$$
\text { Resistance }\left(\text { dynes } / \mathrm{sec} . / \mathrm{cm} .-^{5}\right)=\frac{\text { mean pulmonary arterial pressure }(\mathrm{mm} . \mathrm{Hg}) \times 1332}{\text { cardiac output }(\mathrm{ml} . / \mathrm{sec} \text {. })}
$$

It is realized that the validity of this procedure is not beyond question because it may not be accurate in the presence of vasomotor changes or turbulent flow across a stenosed valve: it has been used only as a rough index.

\section{RESULTS}

A typical result is shown in Fig. 1. The initial levels of pulmonary and systemic arterial pressures were 74 and $125 / 80 \mathrm{~mm}$. $\mathrm{Hg}$ respectively. At this time, the cardiac output was $3 \cdot 11 . / \mathrm{min}$, and total pulmonary resistance 1910 dynes. $/ \mathrm{sec} . / \mathrm{cm} .^{-5}$

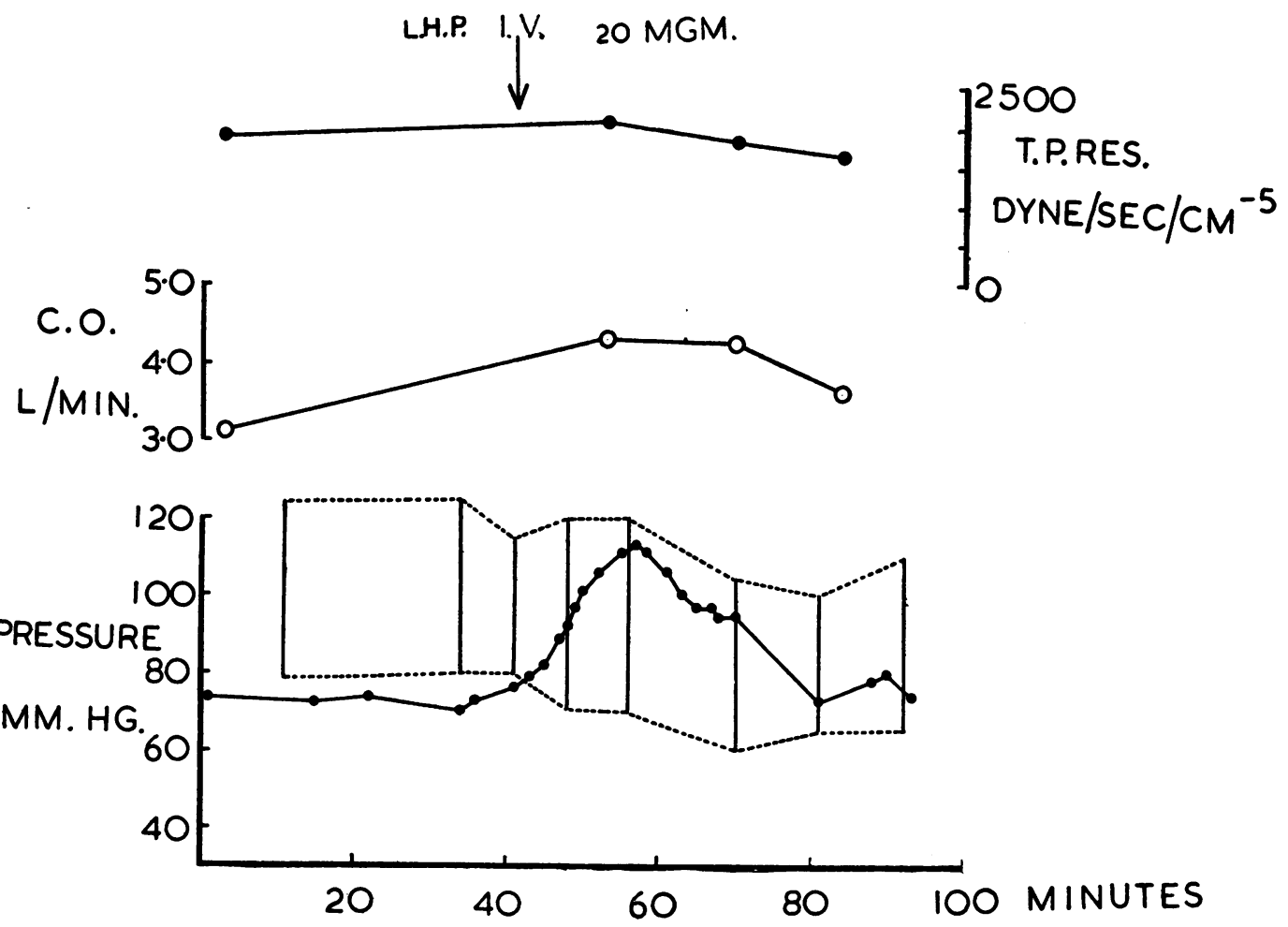

Fig. 1.-Subject M.D. 23/3/53. Response of pulmonary arterial pressure, systemic blood pressure, cardiac output, and total pulmonary resistance to $20 \mathrm{mg}$. 1-hydrazinophthalazine.

After administration of 1-hydrazinophthalazine the mean pulmonary arterial pressure rose rapidly, reaching a maximum value of $113 \mathrm{~mm}$. $\mathrm{Hg} 16$ minutes after the injection. At the same time the cardiac output rose to 4.31 . $/ \mathrm{min}$; during the next 35 minutes cardiac output and mean pulmonary artery pressure gradually fell, returning nearly to their control levels. The systemic pressure showed a gradual fall to a level of $100 / 65 \mathrm{~mm}$. Hg during this time, but unlike the pulmonary arterial pressure, showed no sign of returning to the control level. The total pulmonary resistance showed a rise from 1910 to 2090 dyne. $/ \mathrm{sec} . / \mathrm{cm} .^{-5}$ with a subsequent fall to 1640 dyne./sec. $/ \mathrm{cm} .^{-5}$

A similar pattern was shown by 8 of the 9 patients with mitral disease; subject C. L. who had little if any stenosis of the valve and pulmonary arterial pressure and pulmonary resistance within 
normal limits, showed an insignificant change in pulmonary arterial pressure and a slight decrease in total pulmonary resistance. The initial values, and values at the times of maximal observed pulmonary pressor effect in all subjects, are shown in Table I. The pulse rate rose in the 9 subjects in whom it was measured. The cardiac output also rose in all cases, though the increase was small, and of doubtful significance, in three. The increases in heart rate and in pulmonary artery pressure

TABLE I

Influence of 1-hydrazinophthalazine on Pressures in the Pulmonary Circulation and on Cardiac OutPut

\begin{tabular}{|c|c|c|c|c|c|c|c|c|c|c|}
\hline \multirow{3}{*}{ Subject } & \multirow{3}{*}{ Age } & \multirow{3}{*}{ Diagnosis } & \multirow{3}{*}{ Rhythm } & \multirow{3}{*}{$\begin{array}{l}\text { Pulmon- } \\
\text { ary cap- } \\
\text { illary } \\
\text { pressure } \\
(\mathrm{mm} . \mathbf{H g})\end{array}$} & \multicolumn{4}{|c|}{ Percentage alteration } & \multirow{2}{*}{\multicolumn{2}{|c|}{$\begin{array}{l}\text { Blood } \\
\text { pressure }\end{array}$}} \\
\hline & & & & & \multirow{2}{*}{$\begin{array}{c}\text { Pulmonary } \\
\text { arterial } \\
\text { pressure } \\
\text { (mean) }\end{array}$} & \multirow{2}{*}{$\begin{array}{c}\text { Total } \\
\text { pulmonary } \\
\text { resistance }\end{array}$} & \multirow{2}{*}{$\begin{array}{c}\text { Cardiac } \\
\text { output }\end{array}$} & \multirow{2}{*}{ Pulse } & & \\
\hline & & & & & & & & & Cont. & L.H.P. \\
\hline M.D. (F) & 28 & M.S. (c) & $\mathbf{S}$ & $23 \cdot 5$ & +53 & +9 & +39 & - & $125 / 80$ & $100 / 75$ \\
\hline M.B. (F) & 46 & M.S. & AF & $21 \cdot 7$ & +49 & +11 & +33 & +47 & $135 / 100$ & $130 / 95$ \\
\hline I.M. (F) & 44 & M.S. (c) & $\mathbf{S}$ & 11 & +61 & +50 & +7 & +57 & $125 / 80$ & $120 / 75$ \\
\hline M.W. (F) & 38 & M.S. (c) & A.F & 18 & +24 & +16 & +6 & +33 & $120 / 75$ & $105 / 60$ \\
\hline E.T. (F) & 47 & M.S. & $\mathbf{S}$ & 12.5 & +84 & - & - & +63 & $120 /$ & $90 /$ \\
\hline G.C. (M) & 33 & M.S., M.I. & AF & 一 & +44 & $+34 \cdot 5$ & +7 & +42 & $128 / 80$ & $105 / 55$ \\
\hline W.L. (M) & 43 & M.S., M.I. & AF & - & +73 & +22 & +42 & +36 & 一 & 一 \\
\hline A.C. (F) & 30 & M.S., M.I. & $\mathbf{S}$ & 26 & +40 & +16 & +20 & +45 & $105 / 65$ & $100 / 50$ \\
\hline J.J. (F) & 52 & M.S., M.I. (c) & AF & $13 \cdot 2$ & +47 & +43.4 & +3 & +48 & $135 / 80$ & $100 / 65$ \\
\hline C.L. (F) & 26 & M.I. & $\mathbf{S}$ & - & +13 & -17 & +38 & +23 & $150 / 80$ & $150 / 80$ \\
\hline A.G. (M) & 61 & H.T. & $\mathbf{S}$ & 13 & +4.5 & -17 & +28 & +18 & $190 / 130$ & $174 / 130$ \\
\hline C.W. (M) & 68 & H.T. & $\mathbf{S}$ & - & -17 & -51 & +26 & +7 & $230 / 130$ & $120 / 64$ \\
\hline
\end{tabular}

M.S. = mitral stenosis. H.T. =hypertension. M.I.=mitral incompetence. $\mathrm{S}=$ sinus rhythm. (c) indicates confirmed at operation. $\mathbf{A F}=$ atrial fibrillation.

Dosage of L.H.P. $20 \mathrm{mg}$. except in Cases I.M. and A.C. in which it was 15 and $10 \mathrm{mg}$. respectively.

began about six minutes after the drug had been given. In most cases the maximum change in heart rate and pulmonary artery pressure occurred close to one another; the times of maximum effect varied from 10 to 50 minutes in different patients. The rise in pulmonary arterial pressure lasted for periods of 35 to 80 minutes; the tachycardia and systemic blood pressure fall were of rather longer duration, particularly in two cases. A fall in systemic blood pressure was observed in all patients except C.L.; in two patients the fall was so small as to be insignificant.

A severe fall in systemic blood pressure induced by 1-hydrazinophthalazine, as mentioned by Werko et al. (1954), was encountered in one case, examined late in the series; the investigation was terminated when the patient developed severe hypotension, and has not been included in the series. Apart from this, the only ill effect noted was the development of widespread pulmonary crepitations, suggestive of incipient pulmonary œdema, at the time when the pulmonary artery pressure was at its highest level, in subjects M.B. and E.T.

The increase in pulmonary arterial pressure was related to the initial level of pulmonary arterial 


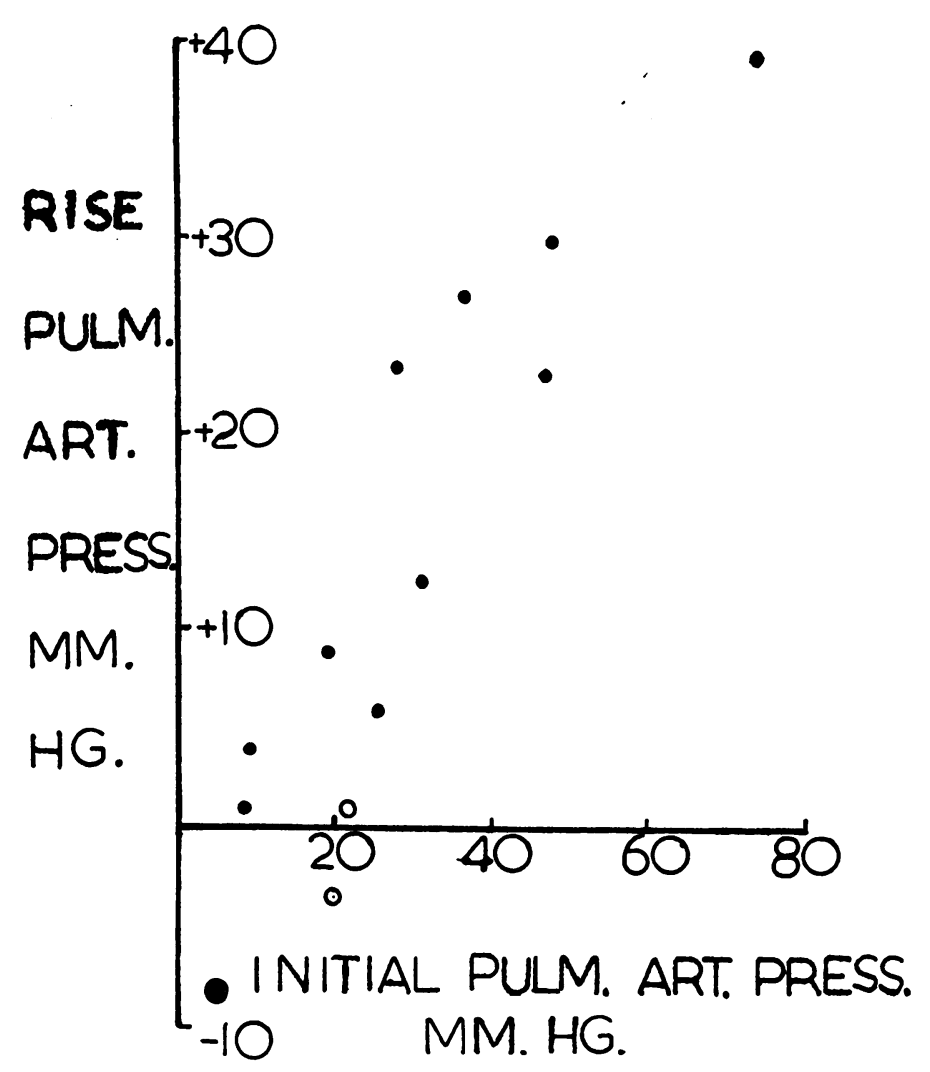

FIG. 2.-Relationship between initial level of pulmonary arterial pressure and rise of pulmonary arterial pressure after administration of 1-hydrazinophthalazine. Closed circles indicate subjects with mitral disease, open circles hypertensive subjects.

pressure (Fig. 2). Subjects with a high control level showed a greater increase than those in whom the basal level was low. In this and subsequent figures the closed circles represent patients with mitral disease, and the open circles represent the values obtained in the two hypertensive subjects. In one of the hypertensives there was a fall in pulmonary arterial pressure with a large fall in systemic blood pressure. In the other the rise in pulmonary artery pressure was much smaller than that observed in the mitral patients with comparable pulmonary arterial pressures. In both cases the cardiac output rose after 1-hydrazinophthalazine; the pulse rate also increased but the rise was less than in the patients with mitral disease.

\section{Discussion}

The principal factors that may be concerned in the rise of pulmonary arterial pressure are pulmonary vasoconstriction, increase in cardiac output, and increase in pulse rate. In the absence of information about changes in the pulmonary "capillary" pressure, the part played by possible constriction of the pulmonary arterioles cannot be assessed. The development of incipient pulmonary œdema in two subjects suggests that, in them at least, the pulmonary " capillary " pressure rose following the administration of the drug. If this were true of all cases, it would indicate that vasoconstriction, if it occurred at all, was not the only factor responsible for the increase in pulmonary hypertension. Araujo and Lukas (1952) found large increases in pulmonary " capillary" 


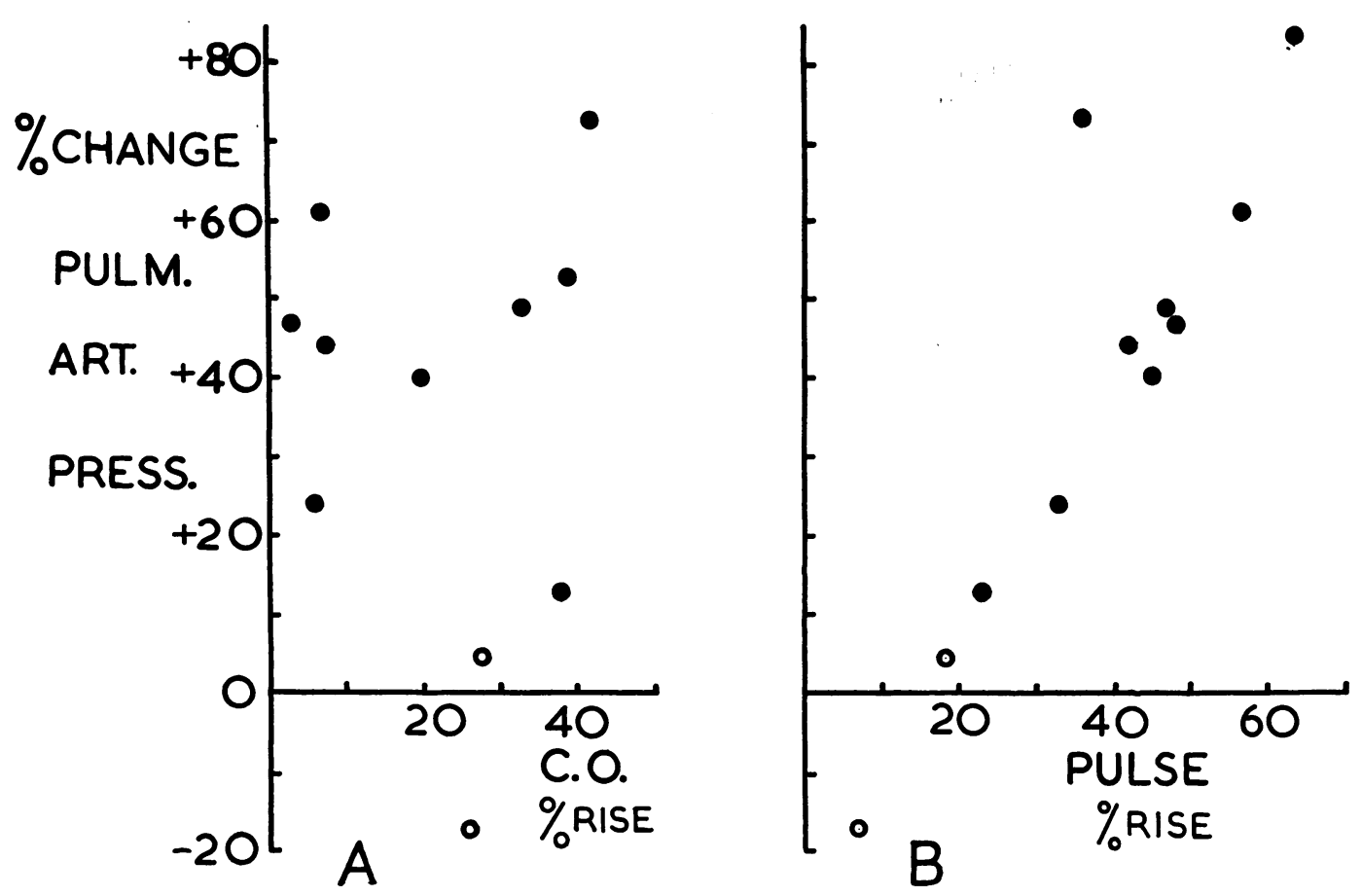

FIG. 3.-A. Percentage increase in pulmonary arterial pressure plotted against percentage increase in cardiac output. B. Percentage increase in pulmonary arterial pressure plotted against percentage increase in pulse rate. Closed circles represent subjects with mitral disease, open circles hypertensive subjects.

pressure in mitral stenosis during exercise, which were not prevented by increased pulmonary vascular (arteriolar) resistance.

Cardiac output was increased in all our subjects, though the increase was very small in three. In normal subjects undertaking exercise the pulmonary artery pressure does not rise above the upper limit of normal until the flow exceeds approximately three times the basal flow (Cournand, 1950). This implies that vasodilatation occurs in the pulmonary system of normal subjects with exercise. In mitral stenosis the capacity to tolerate an increased cardiac output is impaired, so that, even where there is little or no pulmonary hypertension at rest, a moderate degree of effort commonly causes a distinct rise in pulmonary arterial pressure. In Fig. 3 the percentage increase in cardiac output in our cases is plotted against the percentage increase in pulmonary arterial pressure. There is no relationship between the two variables $(r=+0 \cdot 132, p>0 \cdot 10)$. This argues against the pressure rise being simply a manifestation of increased flow through a relatively inflexible pulmonary vascular system, although the increased output probably plays a part in some cases. It is also evident from Table I that a high initial pressure or resistance is not necessarily associated with inability to raise the cardiac output in response to administration of 1-hydrazinophthalazine.

It is probable that in mitral stenosis the whole period of diastole following the opening of the mitral valve is taken up with inflow into the ventricle (Wiggers, 1923). This contrasts with the state of affairs in normal subjects, in whom most of the ventricular filling takes place early in diastole. Increase in pulse rate from 80 to 140 may shorten the duration of diastole by as much as 12 seconds each minute (Gorlin et al., 1951). In mitral stenosis in such circumstances cardiac output can only be maintained or augmented by increasing the rate of flow through the valve during diastole; this in turn means that the pressure gradient across the valve must increase, so that back pressure develops in the pulmonary vascular system. In this series the increase in pulse rate at the time of 
maximal pulmonary arterial pressure was significantly related to the rise in pulmonary arterial pressure $(r=+0.761, p<0.02)$. Tachycardia may not be the whole explanation for the pressure rise, because in some subjects the tachycardia lasted rather longer than the rise in pulmonary artery pressure. The degree of tachycardia was noticeably less in the two cases of hypertension. The response was not related to the type of rhythm, and it is interesting to observe that the increase in heart rate in subjects with atrial fibrillation was similar to the rise in subjects in sinus rhythm. The hypertensive effect of 1-hydrazinophthalazine on the pulmonary circulation of subjects with mitral disease is probably the result of the interaction of several factors, of which the most important seem to be the degree of initial pulmonary hypertension and the degree of tachycardia following the administration of the drug. It has been stated that the incidence of hypertension in mitral stenosis is not significantly different from that in a control hospital population (Gray, 1954), and in a few instances, hypertension may be the cause of death.

The results of this investigation suggest that the use of 1-hydrazinophthalazine is contraindicated in mitral disease, as it raises cardiac rate and output and pulmonary arterial pressure, so increasing the load on the right ventricle. It may predispose towards the development of pulmonary œdema.

\section{SUMMARY}

Administration of 1-hydrazinophthalazine to ten patients with mitral disease was followed by elevation of the pulmonary arterial pressure, increased pulse rate and cardiac output, and fall in systemic blood pressure.

It is suggested that 1-hydrazinophthalazine should not be used in the treatment of hypertension associated with mitral disease, as it is likely to increase the load on the right ventricle, and may even cause pulmonary œdema.

We are grateful to Dr. R. J. Duthie for encouragement and for permission to investigate patients under his care. We wish to thank Dr. T. N. Morgan for helpful criticism. Apresoline was kindly supplied by Mr. J. Lawrie of Ciba Laboratories.

\section{REFERENCES}

Araujo, J., and Lukas, D. S. (1952). J. clin. Invest., 31, 1082.

Cournand, A. (1950). Circulation, 2, 641 .

Gorlin, R., Lewis, B. M., Haynes, F. W., Spiegl, R. J., and Dexter, L. (1951). Amer. Heart J., 41, 834.

Gray, I. R. (1954). Brit. Heart J., 16, 165 .

Roughton, F. J. W., and Scholander, P. F. (1943). J. Biol. Chem., 148, 541.

Werkö, L., Varnauskas, E., Ek, J., Bucht, H., Thomasson, B., Bergstrom, J., and Eliasch, H. (1954). Circulation, 9, 700 .

Wiggers, C. J. (1923). Circulation in Health and Disease. 2nd ed., Lea and Febiger, Philadelphia, p. 545. 